\title{
Intoxicação experimental por Senecio brasiliensis (Asteraceae) em eqüinos ${ }^{1}$
}

\author{
Célso Pilati ${ }^{2}$ e Claudio S.L. Barros ${ }^{3 *}$
}

\begin{abstract}
Pilati C. \& Barros C.S.L. 2007. [Experimental poisoning by Senecio brasiliensis (Asteraceae) in horses.] Intoxicação experimental por Senecio brasiliensis (Asteraceae) em eqüinos. Pesquisa Veterinária Brasileira 27(7):287-296. Departamento de Patologia, Universidade Federal de Santa Maria, 97105-900 Santa Maria, RS, Brazil. E-mail: claudioslbarros@uol.com.br

Fourteen 4 to 22-year-old mixed breed horses weighing 230-475 kg were experimentally fed the dried aerial parts of Senecio brasiliensis (Spreng.) collected in its sprouting stage. A 15-year-old horse served as non-plant-fed control. Small amounts of the dried plant material were admixed in the ration given to the horses; larger amounts were grounded, admixed with water and force fed through nasogastric intubation. Liver biopsies were periodically performed in 11 horses. Nine horses died with signs or lesions of the poisoning after having received amounts of the plant corresponding to $0.87 \%, 1.5 \%$ (single administrations), $1.74 \%$ (two weekly administrations), $3.0 \%$ (three daily administrations), $7.42 \%$ (17 weekly administrations), $8.9 \%$ (284 daily administrations), $9.66 \%$ (82 daily administrations) and $9.30 \%$ ( 43 weekly administrations) of their body weight. Two horses which received amounts of the plant corresponding to $15.0 \%$ (30 and 60 daily administrations) of their body weight died during the experiments due to unrelated causes. Three horses which received amounts of the plant corresponding to $0.5 \%$ and $1.0 \%$ (single administrations), and $15.0 \%$ (240 daily administrations) of their body weight, and the control horse survived without any clinical signs. The disease induced by the plant had a clinical course of 1-30 days and was characterized by anorexia, jaundice and neurological signs of hepatic encephalopathy. Weight loss was observed in the more protracted cases. Necropsy findings included marked enhancement of the lobular pattern of the livers or those were firm and dark-red. Hemorrhages were frequent and more conspicuous on the subcutis, serosal surfaces and in the gastrointestinal mucosa. Edema occurred in the submucosa of the gastrointestinal tract and in body cavities. Histologically, the livers of horses that ingested relatively larger amounts of the plant for short periods of time had zonal coagulative necrosis and centrilobular to massive hemorrhages. Moderate to marked hepatomegalocytosis and mild to moderate fibrosis were seen in 4 horses which ingested small amounts of the plant for longer periods. Cholestasis and hemosiderosis were observed in the liver of 8 horses, neutrophilic aggregates in 6 and acidophilic intranuclear pseudoinclusion bodies in hepatocytes of 3 horses. Changes suggestive of hepatic encephalopathy were observed in the brain of 6 horses. The earliest detected change in the liver biopsies was vacuolization of hepatocyte nuclei followed by apoptotic loss of hepatocytes, hepatomegalocytosis, infiltration of neutrophils and centrolobular necrosis. Occasionally hepatocellular acidophilic intranuclear pseudo-inclusion bodies and, in more protracted cases, slight fibrosis were seen. No changes were observed in the liver biopsies of the 3 plant-fed horses that survived, nor on the 2 horses that died of unrelated causes. The control horse had no clinical signs.
\end{abstract}

INDEX TERMS: Poisonous plants, Senecio brasiliensis, Asteraceae, diseases of horses, pathology.

\footnotetext{
${ }^{1}$ Recebido em 29 de dezembro de 2006.

Aceito para publicação em 5 de janeiro de 2007.

Parte da Tese de Mestrado do primeiro autor, Programa de Pós-Graduação em Medicina Veterinária (PPGMV), Universidade Federal de Santa Maria (UFSM), área de concentração em Patologia Veterinária.
}

\footnotetext{
${ }^{2}$ Universidade do Estado de Santa Catarina, Centro Agroveterinário, Campus 3, Av. Luis de Camões 2090, Lages, SC 88520-000, Brasil. E-mail: a2cp@cav.udesc.br

${ }^{3}$ Depto Patologia, UFSM, Santa Maria, RS 97105-900, Brasil. "Autor para correspondência: claudioslbarros@uol.com.br
} 
RESUMO.- As partes aéreas dessecadas de Senecio brasiliensis (Spreng.) colhidas em estágio de brotação foram administradas a 14 eqüinos de raça mista, com idades de 4-22 anos e pesos de 230-475 kg. Um eqüino de 15 anos, que não recebeu a planta, serviu de controle. Pequenas quantidades da planta eram misturadas à ração oferecida aos eqüinos; quantidades maiores eram moídas, misturadas em água e administradas por sonda nasogástrica. Biópsias hepáticas foram periodicamente realizadas em 11 equiinos. Nove equiinos morreram com sinais ou lesões da intoxicação após receberem quantidades da planta correspondente a $0,87 \%, 1,5 \%$ (administrações únicas), 1,74\% (duas administrações semanais), 3.0\% (três administrações diárias), 7.42\% (17 administrações semanais), 8.9\% (284 administrações diárias), 9.66\% (82 administrações diárias) e 9,30\% (43 administrações semanais) de seus pesos corporais. Dois eqüinos que receberam quantidades da planta correspondentes a 15,0\% (30 e 60 administrações diárias) de seus pesos corporais morreram durante o experimento por causas não relacionadas à intoxicação. Três eqüinos que receberam quantidades da planta correspondentes a 0,5\% e 1.0\% (administrações únicas), 15.0\% (240 administrações diárias) de seus pesos corporais e o eqüino controle sobreviveram sem apresentar sinais clínicos. A doença clínica induzida pela planta teve uma evolução de 1-30 dias e foi caracterizada por anorexia, icterícia, e sinais neurológicos de encefalopatia hepática. Perda de peso foi observada nos casos de evolução clínica mais longa. Os achados de necropsia incluíam acentuação do padrão lobular na superfície natural e de corte dos fígados ou eram firmes e vermelho-escuros. Hemorragias disseminadas eram freqüentes, mas mais conspícuas no tecido subcutâneo, superfícies serosa e mucosa do trato gastrintestinal. Edema era observado na submucosa do trato gastrintestinal e nas cavidades orgânicas. Microscopicamente, o fígado dos equiinos que ingeriram quantidades maiores da planta por períodos relativamente curtos mostrava necrose coagulativa e hemorragia com cuja distribuição variava de centrolobular a massiva. Hepatomegalocitose moderada ou acentuada e fibrose discreta a moderada foi observada em 4 equiinos que ingeriram pequenas quantidades da planta por períodos mais prolongados. Colestase e hemossiderose foram observadas no fígado de 8 eqüinos, agregados de neutrófilos no de 6 , e pseudo-inclusões acidofílicas intranucleares ocorreram nos hepatócitos do fígado de 3 eqüinos. Alterações sugestivas de encefalopatia hepática foram observadas no encéfalo de 6 eqüinos. A lesão mais precoce observada nas biópsias hepáticas foi vacuolização dos núcleos de hepatócitos seguida por perda de hepatócitos por apoptose, hepatomegalocitose, infiltração por neutrófilos e necrose centrolobular. Ocasionalmente, observavam-se pseudo-inclusões acidofílicas intranucleares nos hepatócitos e, em casos mais crônicos, leve fibrose. Não foram observadas alterações nas biópsias hepáticas dos 4 equiinos que receberam a planta e que sobreviveram, nem nas biópsias hepáticas dos 2 equiinos que morreram de causas não relacionas à intoxicação. $\mathrm{O}$ eqüino controle não apresentou sinais clínicos.

TERMOS DE INDEXAÇÃO: Plantas tóxicas, Senecio brasiliensis, Asteraceae, doenças de eqüinos, patologia.

\section{INTRODUÇÃO}

As intoxicações por plantas em animais de fazenda têm grande importância na pecuária do Rio Grande do Sul (Riet-Correa \& Medeiros 2001, Rissi et al. 2007). Nesse Estado, plantas do gênero Senecio são as principais causadoras de perdas econômicas em bovinos (Rissi et al. 2007) e espécies já comprovadas como tóxicas para bovinos incluem Senecio brasiliensis (Tokarnia \& Döbereiner 1984), S. heterotrichius, S. cisplatinus, $S$. selloi (Méndez et al.1987) e $S$. oxyphyllus (Driemeier et al. 1991, Driemeier \& Barros 1992, Barros et al. 1992, Liddell et al. 1992); são invasoras comuns de pastagens e de frequiência muito alta na maior parte do Estado; seu principio ativo são ésteres de amino-alcóois derivados do núcleo heterocíclico pirrolizidina e conhecidos coletivamente como alcalóides pirrolizidínicos, APs (McLean 1970). A ingestão de plantas que contêm APs produz em ovinos, bovinos e eqüinos quadros hepatotóxicos agudos, subagudos e crônicos (Kingsbury 1964, Tokarnia \& Döbereiner 1984), embora os casos espontâneos sejam, na grande maioria das vezes, crônicos (Barros et al. 1992).

No Brasil, S. brasiliensis é a espécie de Senecio mais freqüiente, com larga distribuição na Região Sul e também em áreas altas e frescas da Região Sudeste. Seu habitat são campos nativos e cultivados (Tokarnia \& Döbereiner 1984) e seu conteúdo em APs inclui integerrimina e retrorsina (Méndez et al. 1990). A intoxicação experimental por S. brasiliensis em bovinos foi detalhadamente descrita (Tokarnia \& Döbereiner 1984) e surtos espontâneos da intoxicação nos quais $S$. brasiliensis é uma das espécies envolvidas são freqüentes em bovinos no Rio Grande do Sul (Barros et al. 1987, Méndez et al. 1987, Driemeier et al. 1991, Barros et al 1992, 2007). Documentações da intoxicação espontânea por espécies de Senecio em eqüinos no Brasil são mais raras, mas surtos têm sido descritos nas Regiões Sudeste (Carvalho \& Maugé 1946) e Sul (Curial \& Guimarães 1958, Gava \& Barros 1997).

Os objetivos desse trabalho foram (1) determinar experimentalmente a sensibilidade dos eqüinos a $S$. brasiliensis, estabelecendo as quantidades tóxicas da planta; (2) determinar o quadro clinico, anatomopatológico e histopatológico da intoxicação; e (3) estabelecer, através de biópsias hepáticas, a sequiência do desenvolvimento das lesões no fígado.

\section{MATERIAL E MÉTODOS}

\section{Animais de experimentação}

Os experimentos foram realizados nos anos de 1989-1990 no Laboratório de Patologia Veterinária da Universidade Federal de Santa Maria. Foram utilizados 14 eqüinos, sem raça definida, com idades de 4-22 anos com pesos variando de $230-475 \mathrm{~kg}$. Os eqüinos eram mantidos em piquetes onde não havia Senecio spp. Diariamente eram fechados em baias de alvenaria para receber a planta, ou quando adoeciam. Todos os equiinos recebiam de $2-3 \mathrm{~kg}$ de ração concentra$\mathrm{da}^{4}$ por dia. Dos eqüinos submetidos a experimentos com duração acima de 30 dias, foram colhidas fezes para exames parasitológicos que eram repetidos a cada 2 meses. Nos casos em que se observa-

\footnotetext{
${ }^{4}$ Ração para eqüinos Royal-Horse (Socil), Rua Mauricio Cardoso 952. Caixa Postal 255, Esteio, RS.
} 
vam contagens iguais ou superiores a 500 ovos por grama de fezes, o eqüino era tratado com anti-helmíntico ${ }^{5}$.

Diariamente era feita a inspeção clínica dos eqüinos considerando-se, principalmente, o apetite, a disposição em se movimentar, o estado de nutrição e a coloração das mucosas externas. Os eqüinos eram pesados mensalmente ou quando havia evidência morfológica de uma alteração significativa no peso.

Devido à intoxicação por alcalóides pirrolizidínicos ser, em geral, reconhecidamente crônica e progressiva, podendo os animais adoecer em várias semanas ou meses após a última ingestão da planta (Kingsbury 1964, Giles 1983), os eqüinos que não morreram durante a administração da planta foram observados por um período mínimo de 107 dias após a última administração. Um eqüino tratado de maneira semelhante, mas que não recebeu a planta foi usado como controle.

\section{A planta, métodos e locais de colheita}

A descrição botânica da planta, identificada como Senecio brasiliensis $^{6}$ já foi anteriormente publicada (Tokarnia \& Döbereiner 1984).

Os $10 \mathrm{~cm}$ superiores da planta em brotação foram colhidos no município de Santa Maria, RS, em junho-julho de 1988. A planta foi colhida em vários locais de uma mesma região que fica aproximadamente $25 \mathrm{~km}$ ao norte da sede do município ao longo da Rodovia BR 158. Após a colheita, a planta foi secada à sombra e estocada em local arejado à temperatura ambiente.

A relação de peso entre a planta verde e a planta dessecada foi de $5: 1 ; S$. brasiliensis mantém a sua toxidez mesmo quando dessecado (Tokarnia \& Döbereiner 1984); embora todas as administrações S. brasiliensis aos eqüinos deste experimento tenham sido feitas com

\footnotetext{
${ }^{5}$ Mebendazole Univet Eqüinos (UNIVET), Rua Climaco Barbosa 700, Bairro Cambuci, São Paulo, SP. Equitac Plus Smith and Kline, Av. das Américas 790, $52^{\circ}$ andar, Rio de Janeiro, RJ.

${ }^{6}$ Identificação botânica pela Dra. Graziela Maciel Barroso, Jardim Botânico, Rio de Janeiro, RJ.
}

a planta seca, todas as quantidades de planta mencionadas neste trabalho referem-se ao correspondente em planta verde.

\section{Métodos de administração da planta}

Em administrações prolongadas de pequenas quantidades, a planta era misturada à ração concentrada e oferecida aos eqüinos. Quando os eqüinos não consumiam toda a ração a parte rejeitada era pesada e não entrava no cálculo da quantidade total de planta ingerida. Administrações de quantidades maiores da planta eram feitas através de sonda nasogástrica de $1,5 \mathrm{~cm}$ de diâmetro, acoplada a um funil. Para as administrações por sonda, a planta era previamente moída em um moinho Thomaz Willey modelo 4, com malha de $1 \mathrm{~mm}$ e misturada com água imediatamente antes da administração. As doses de planta administradas eram reajustadas cada vez que o eqüino apresentava uma variação no peso igual ou superior a $10 \mathrm{~kg}$.

Os dados referentes aos eqüinos do experimento, quantidades de planta administrada e método de administração constam do Quadro 1.

\section{Métodos em patologia}

Biópsias hepáticas foram realizadas por punção transtorácica com uma agulha de Menghini. Os eqüinos foram submetidos à biópsia hepática em várias oportunidades durante os experimentos (Quadro 2) com a finalidade de observar-se a sequiência das alterações no fígado. $\mathrm{O}$ material colhido em cada biópsia pesava em torno de $0, \mathrm{lg}$, era fixado em formol, incluído em parafina, cortado a $5 \mathrm{~mm}$ e corado pela hematoxilina e eosina (HE), tricrômico de Masson e Gridley para retículo.

Todos os eqüinos que morreram, com exceção do Eqüino 8, foram necropsiados. Sistematicamente, foram colhidos fragmentos de fígado, pulmão, coração, duodeno, jejuno, íleo, cólon maior, ceco, cólon menor, baço, linfonodos, tireóide, adrenal, hipófise, rim, bexiga e estômago. $\mathrm{O}$ encéfalo foi colhido inteiro e fixado em formol a $10 \%$ por, no mínimo, dois meses; após esse período era seccionado em cortes transversais seriados com intervalos de $1 \mathrm{~cm}$. A superfície de corte de todas as secções era, então, examinada macroscopicamente. Desses cortes transversais, foram sistematicamente proces-

\begin{tabular}{ccccccccc}
\multicolumn{2}{c}{ Quadro } & \multicolumn{2}{c}{ Intoxicação experimental por Senecio brasiliensis em eqüinos. Dados dos eqüinos que receberam a planta, } \\
\multicolumn{7}{c}{ quantidades da planta administrada e modo de administração }
\end{tabular}

${ }^{\mathrm{a}} \mathrm{A}$ planta foi administrada em estado seco, porém os valores constantes no Quadro referem-se ao correspondente em planta verde. Um grama de planta seca corresponde a $5 \mathrm{~g}$ de planta verde. ${ }^{b}$ Macho castrado. ${ }^{\mathrm{C}}$ Misturada à ração. ${ }^{\mathrm{d}}$ Nestes eqüinos, as doses diárias eram multiplicadas

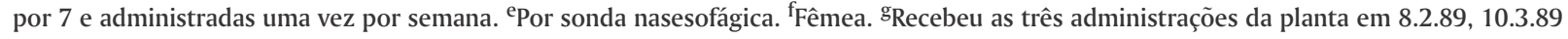
e 24.3.89. 
Quadro 2. Intoxicação experimental por Senecio brasiliensis em eqüinos. Freqüência de realização das biópsias hepáticas

\begin{tabular}{|c|c|c|}
\hline Eqüino & $\begin{array}{l}\text { Total da planta } \\
\text { ingerida em relação } \\
\text { ao peso corporal (\%) }\end{array}$ & Frequiência com que foram realizadas as biópsias hepáticas ${ }^{\mathrm{a}}$ \\
\hline 01 & 0,50 & B3 - B31 - B53 - B93 \\
\hline 02 & 9,30 & B51 - B82 - B143 - B172 - B197 - B249 - B314 - B335 - B343 - B353 - B358 - B406 - B464 - B478 - B498 \\
\hline 03 & 8,90 & B63 - B145 - B174 - B199 - B251 \\
\hline 04 & 15,00 & B31 - B62 - B93 - B113 - B122 - B151 - B176 - B227 - B241 - B276 - B292 - B316 - B331 - B349 - B387 - B442 \\
\hline 05 & 1,00 & В0 - B9 - B24 - B62 - B83 - В92 - В122- B147 \\
\hline 06 & 7,42 & $\mathrm{~B} 21-\mathrm{B} 59-\mathrm{B} 66-\mathrm{B} 69-\mathrm{B} 80-\mathrm{B} 89-\mathrm{B} 110$ \\
\hline 07 & 9,66 & B17 - B24 - B47 - B76 \\
\hline 08 & 15,00 & B0 - B3 - B6 - B16- B55 - B80 - B131 - B167-B190-B205-B261 - B317 \\
\hline 11 & 3,00 & B0 - B23 - B30 \\
\hline 12 & 15,00 & $\mathrm{~B} 0-\mathrm{B} 14-\mathrm{B} 51-\mathrm{B} 66-\mathrm{B} 103-\mathrm{B} 121-\mathrm{B} 159-\mathrm{B} 171-\mathrm{B} 186-\mathrm{B} 204-\mathrm{B} 239$ \\
\hline 13 & 1,50 & $\mathrm{~B} 0-\mathrm{B} 1-\mathrm{B} 2$ \\
\hline
\end{tabular}

${ }^{a} O$ dia do início da administração da planta foi considerado o dia zero do experimento. B0 significa biópsia hepática realizada antes do início da administração da planta; os outros números após o B (biópsia) indicam o n úmero de dias transcorridos após o início da administração da planta. Nos Eqüinos 9, 10 e 14 foi realizada apenas a biópsia pré-experimento (B0).

Quadro 3. Intoxicação experimental por Senecio brasiliensis em eqüinos. Sinais clínicos e evolução do quadro clínico ${ }^{\mathrm{a}}$

\begin{tabular}{|c|c|c|c|}
\hline Eqüino & $\begin{array}{c}\text { Início dos SCb } \\
\text { (dias após a } \\
\text { administração } \\
\text { da planta) }\end{array}$ & $\begin{array}{l}\text { Duração } \\
\text { dos SC } \\
\text { (dias) }\end{array}$ & Sinais clínicos \\
\hline 2 & 678 & 30 & Emagrecimento, icterícia, andar a esmo e incoordenado, pressão da cabeça contra objetos. \\
\hline 3 & 284 & 2 & Diarréia profusa, perda de peso, decúbito lateral e morte \\
\hline 5 & 108 & 6 & $\begin{array}{l}\text { Bocejos, mastigação sem alimento na boca, icterícia moderada, anorexia, andar a esmo, so- } \\
\text { nolência, apatia, perda de peso, decúbito lateral e morte }\end{array}$ \\
\hline 7 & 79 & 5 & $\begin{array}{l}\text { Anorexia, apatia, movimentava-se pouco, icterícia moderada, flacidez dos lábios, andarem } \\
\text { círculos, andar a esmo, freqüente atitude de urinar, mucosas congestas, perda de peso, tem- } \\
\text { peratura } 39,1^{\circ} \mathrm{C} \text {, decúbito lateral e morte }\end{array}$ \\
\hline 9 & 3 & 1 & $\begin{array}{l}\text { Apatia, redução do apetite, icterícia acentuada, mucosas marrom-avermelhadas, sudorese, } \\
\text { andar cambaleante, andar a esmo dismetria, tremores musculares, redução dos reflexos pal- } \\
\text { pebrais, pressão da cabeça contra a parede do estábulo, decúbito lateral, movimentos de pe- } \\
\text { dalagem e morte }\end{array}$ \\
\hline 10 & 12 & 1 & $\begin{array}{l}\text { Apatia, diminuição do apetite, icterícia moderada, movimentos verticais incoordenados com } \\
\text { a cabeça, decúbito lateral e morte }\end{array}$ \\
\hline 11 & 50 & 2 & $\begin{array}{l}\text { Anorexia, icterícia moderada, apatia, abatimento, locomovia-se pouco, congestão de muco- } \\
\text { sas, febre, decúbito lateral e morte }\end{array}$ \\
\hline $12^{\mathrm{c}}$ & 15 & - & $\begin{array}{l}\text { Sinais clínicos de cólica: inquietude, sudorese, regurgitação e alimento pelas fossas nasais, } \\
\text { manoteio, rolar sobre o dorso }\end{array}$ \\
\hline 13 & 1 & 4 & $\begin{array}{l}\text { Bocejos, icterícia moderada, congestão de mucosas, abatimento, apatia, anorexia, andar em } \\
\text { círculos, pressão da cabeça contra objetos, contrações freqüentes dos músculos dos lábios, } \\
\text { diminuição dos reflexos palpebrais, dificuldade de deglutição, decúbito lateral, gemidos de } \\
\text { dor e contrações musculares fortes }\end{array}$ \\
\hline 14 & 5 & 3 & $\begin{array}{l}\text { Anorexia, sonolência, perda de peso, icterícia moderada, congestão das mucosas, andar cam- } \\
\text { baleante, temperatura de } 39,1^{\circ} \mathrm{C}\end{array}$ \\
\hline
\end{tabular}

aO Eqüino 12 morreu em conseqüência de dilatação e ruptura gástricas. A duração dos sinais clínicos desse eqüino foi de 6-12 horas. Não foi realizada necropsia no Eqüino 8. O eqüino controle não apresentou alterações clínicas. binais clínicos.

sados para histologia: (1) bulbo na altura do óbex, (2) cerebelo, (3) ponte com pedúnculos cerebelares, (4) mesencéfalo na altura dos colículos rostrais, (5) seção do diencéfalo através da massa intermédia, e (6) córtex frontal na altura do joelho do corpo caloso e dos núcleos da base. Após fixados, fragmentos de todos os órgãos colhidos na necropsia foram incluídos em parafina, cortados a $5 \mathrm{~m}$ e corados pela HE. Cortes de congelação do fígado e rim de todos os equiinos necropsiados foram corados pelo Sudan III para gordura. Cortes de fígado incluídos em parafina foram corados pelo tricrômico de Masson modificado por Goldner para colágeno, Gridley para reticulo e Azul da Prússia (Perls) para hemossiderina.

\section{RESULTADOS}

\section{Sinais clínicos}

Dos 14 eqüinos que receberam a planta, nove morreram (Eqünos 2, 3, 6, 7, 9-11,13,14) apresentar um quadro clínico com evolução de 1-30 dias (Quadro 3). 0 Eqüino 8 que havia recebido administrações diárias de $5 \mathrm{~g} / \mathrm{kg}$ de Senecio brasiliensis durante 335 dias (15\% do peso corporal) não apresentou quaisquer sinais clínicos da intoxicação durante o tempo em que foi observado (335 dias após a última administração da planta); quando esse eqüino morreu não estava mais sendo obser- 


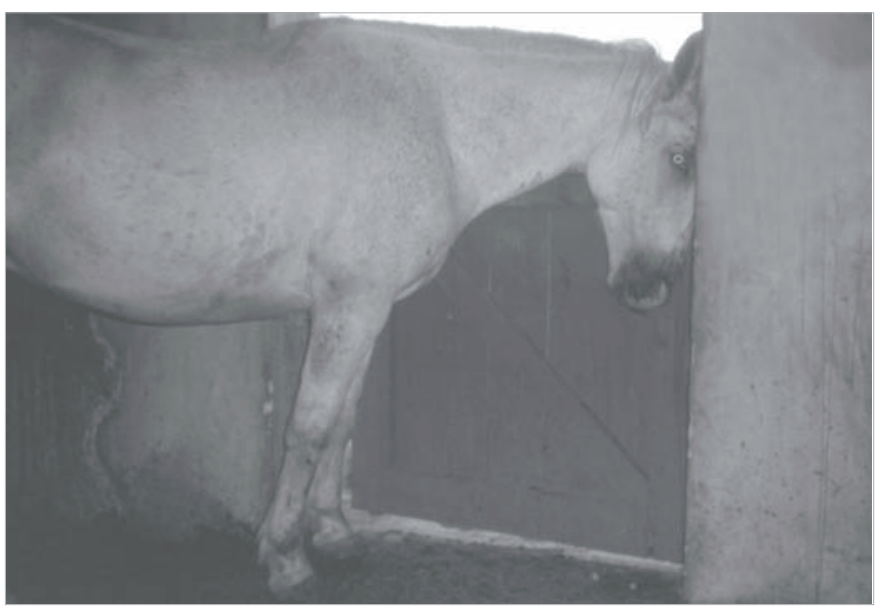

Fig.1. Sinal neurológico caracterizado por pressão da cabeça contra objetos, na intoxicação experimental por Senecio brasiliensis (Eqüino 13).

vado e conseqüentemente não há dados sobre sinais clínicos ou de necropsia. O Eqüino 12 morreu de doença não relacionada à intoxicação. Durante o experimento esse equiino foi cedido para uma aula prática de cólica (distensão do estômago por um balão inflável) e morreu de ruptura gástrica 12 horas após demonstração. Os Eqüinos 1, 4 e 5 e o eqüino controle não adoeceram.
Os sinais clínicos (Quadro 3) iniciavam com diminuição do apetite, anorexia, icterícia, apatia e sonolência. Perda de peso (Equiinos 6, 7 e 14) e elevação da temperatura no dia anterior à morte (Eqüinos 7, 11 e 14) ocorreram em três eqüinos. Sinais clínicos de distúrbios neurológicos ocorreram em sete eqüinos. Esses sinais incluíam andar cambaleante e incoordenação em quatro equiinos $(2,9,13$ e 14) ou em círculos (Equiinos 7 e 13). Três eqüinos (2, 9 e 13) pressionavam a cabeça contra objetos, como a parede da cocheira (Fig.1) ou palanques de cerca, e mostravam diminuição nos reflexos palpebrais. Adicionalmente, um desses eqüinos apresentou, algumas horas antes da morte, intensa sudorese, tremores musculares, dismetria, movimentos de pedalagem (Eqüino 9) e outro mostrou contrações periódicas dos músculos labiais, dificuldade de deglutição, contrações e tremores musculares e gemidos de dor (Eqüino 13). Alguns eqüinos mostravam caminhar compulsivo a esmo durante longos períodos, sem parar para pastar ou beber água (Eqüinos 2, 6, 9 e 7), ou permaneciam imóveis por longo tempo (Eqüinos 2, 7 e 11); no caso do Eqüino 7, essa atitude podia se alternar com caminhar compulsivo. O Eqüino 10 mostrava ocasionalmente movimentos verticais bruscos e incoordenados com a cabeça. Dois eqüinos (6 e 13) bocejavam freqüentemente e um deles mostrava mastigação contínua sem alimento na boca (Eqüino 6). O Eqüino 7 apresentou flacidez dos lábios, esforços freqüentes para urinar, na maioria das vezes sem sucesso, e pê-

Quadro 4. Intoxicação experimental por Senecio brasiliensis em eqüinos. Principais achados de necropsiaa

\begin{tabular}{|c|c|}
\hline Eqüino & Achados de necropsia \\
\hline 2 & Mau estado de nutrição. Ascite, hidrotórax, hidropericárdio. Fígado diminuído de volume, congesto e firme. \\
\hline 3 & $\begin{array}{l}\text { Estado de nutrição regular, desidratação. Mucosa do cólon maior espessada, de aspecto rugoso, intensamente avermelhada em algumas áreas } \\
\text { com pequenas placas branco-amareladas elevadas. Fígado discretamente endurecido }\end{array}$ \\
\hline 5 & $\begin{array}{l}\text { Estado de nutrição regular. Icterícia. Hemorragias subcutâneas, subendocárdicas, subepicárdicas e subpleurais, nas serosas parietal e visceral } \\
\text { do abdômen; nas mucosas do jejuno, íleo e cólon maior; foco hemorrágico no tronco encefálico. Edemas: das serosas parietal e visceral do } \\
\text { abdômen, mesentério, mesocolo, parede do cólon maior e ceco. Fígado: discretamente endurecido, vermelho escuro, congesto, com discre } \\
\text { ta acentuação do padrão lobular nas superfícies capsular e de corte }\end{array}$ \\
\hline 7 & $\begin{array}{l}\text { Estado de nutrição ruim. Icterícia. Hemorragias subendocárdicas e subepicárdicas, perirrenais, no ligamento largo do útero, na medular da } \\
\text { adrenal (hematoma) e na serosa e mucosa do intestino. Edemas: subcutâneo, hidropericárdio, no diafragma, nos tecidos peripancreáticos, no } \\
\text { ligamento entre vértebras e aorta, no ligamento gastresofágico, nos tecidos perirrenais, no ligamento largo do útero, na parede do ceco e } \\
\text { cólon maior. Fígado: discretamente endurecido, marcada acentuação do padrão lobular nas superfícies capsular e de corte }\end{array}$ \\
\hline 9 & $\begin{array}{l}\text { Estado de nutrição bom. Icterícia. Hemorragias: subcutâneas, subepicárdicas, subendocárdicas, das serosas do estômago, do intestino, mesentério } \\
\text { e omento; nas mucosas do duodeno e do cólon maior. Edemas: ascite, hidropericárdio, discreto hidrotórax, nos tecidos peripancreáticos, no } \\
\text { mesentério, na mucosa e submucosa do íleo, ceco e cólon maior, Fígado: superfície lisa, vinhosa. Acentuação do padrão lobular na superfície } \\
\text { capsular. Na superfície de corte apareciam, adicionalmente, áreas amarelas bem delimitadas }\end{array}$ \\
\hline \multirow[t]{2}{*}{10} & Estado nutricional muito bom. Icterícia. \\
\hline & $\begin{array}{l}\text { Hemorragias: subcutânea, subepicárdicas e subendocárdicas, subpleurais (pleura parietal) peritônio parietal, na adrenal, mucosas do ceco. Havia } \\
\text { avermelhamento segmentar da mucosa do duodeno, jejuno e íleo. Edemas: ascite, nos tecidos peripancreáticos, em torno do ligamento gas- } \\
\text { troesplênlco, na parede do íleo e cólon maior, na região subcapsular da adrenal (hematoma). Fígado: congesto, vinhoso escuro com acentua- } \\
\text { ção do padrão lobular nas superfícies capsular e de corte. Áreas amareladas focais bem definidas semelhantes às descritas no eqüino 9, na } \\
\text { superfície de corte }\end{array}$ \\
\hline 11 & $\begin{array}{l}\text { Estado de nutrição regular. Icterícia. Hemorragias: subepicárdicas e subendocárdicas. Edemas: ascite, hidropericárdio, discreto hidrotórax; no } \\
\text { tecido peripancreáticos, nas paredes da parte final do íleo, ceco e cólon maior. Fígado: superfície capsular lisa com acentuação do padrão lo- } \\
\text { bular, que era vista também na superfície de corte }\end{array}$ \\
\hline 12 & Ruptura gástrica ao longo da curvatura maior do estômago; peritonite \\
\hline 13 & $\begin{array}{l}\text { Estado nutricional muito bom. Icterícia. Hemorragias: subcutâneas, subepicárdicas e subendocárdicas, subcapsulares na adrenal e na serosa do } \\
\text { início do duodeno; Edemas: no mesentério, na parede do íleo, ceco e cólon maior. Fígado: levemente tumefeito, acentuação do padrão lobu- } \\
\text { lar nas superfícies capsular e de corte }\end{array}$ \\
\hline 14 & $\begin{array}{l}\text { Estado nutricional bom. Icterícia. Hemorragias: subcutâneas, subepicárdicas e subendocárdicas, nas mucosas gástrica, do cólon maior, na serosa } \\
\text { do cólon menor, subpleurais (pleura visceral) e na medular da adrenal. Edemas: hidropericárdio, ascite, paredes do íleo, cólon maior o ceco. } \\
\text { Fígado: congesto, superfície capsular lisa com aspecto variegado. Superfície de corte com discreto desenho da lobulação }\end{array}$ \\
\hline
\end{tabular}

anão foi realizada necropsia no Eqüino 8 . 
Quadro 5. Intoxicação experimental por Senecio brasiliensis em eqüinos. Lesões macroscópicas extra-hepáticas. Distribuição das hemorragias em oito eqüinos intoxicados

\begin{tabular}{|c|c|c|c|c|c|c|c|c|}
\hline \multirow[t]{2}{*}{ Órgão ou tecido } & \multicolumn{8}{|c|}{ Eqüino } \\
\hline & 03 & 06 & 07 & 09 & 10 & 11 & 13 & 14 \\
\hline Tecido subcutâneo & - & + & - & + & + & - & + & + \\
\hline \multicolumn{9}{|l|}{ Serosas } \\
\hline Subepicárdio & - & + & + & - & + & + & + & + \\
\hline Subendocárdio & - & + & + & + & + & + & + & + \\
\hline Peritônio parietal e mesentério & - & + & - & - & + & - & - & - \\
\hline \multicolumn{9}{|l|}{ Outras serosas } \\
\hline Estômago & - & + & - & + & - & - & - & - \\
\hline Duodeno & - & + & - & + & - & - & - & - \\
\hline Jejuno & - & + & - & + & - & - & - & - \\
\hline Íleo & + & + & - & + & - & - & - & - \\
\hline Cólon maior & - & + & - & + & - & - & - & - \\
\hline Ceco & - & + & - & + & - & - & - & - \\
\hline Cólon menor & - & + & - & + & - & - & - & + \\
\hline \multicolumn{9}{|l|}{ Mucosas } \\
\hline Estômago & - & - & - & - & - & + & - & + \\
\hline Duodeno & - & - & - & + & + & + & - & + \\
\hline Jejuno & - & - & + & - & + & + & - & - \\
\hline Íleo & - & - & + & - & - & - & - & - \\
\hline Cólon maior & + & + & - & + & - & - & - & + \\
\hline Ceco & - & - & + & - & + & - & - & - \\
\hline Cólon menor & - & + & - & + & - & + & - & + \\
\hline Rins & - & - & - & - & - & + & + & + \\
\hline Adrenais & - & + & + & + & + & + & + & + \\
\hline
\end{tabular}

los arrepiados. O Eqüino 3 apresentou diarréia profusa, que produziu perda de peso e marcada desidratação. A morte ocorreu dois dias após o aparecimento da diarréia. Anteriormente, esse eqüino já havia apresentado dois episódios menos graves de diarréia e se recuperado.

\section{Achados de necropsia}

A consistência era leve ou moderadamente mais firme nos fígados dos Eqüinos 2, 3, 6 e 7 e aparentemente normal nos demais equiinos necropsiados. Exceto pelos Eqüinos 2, 3 e 12, os outros eqüinos mostravam acentuação do padrão lobular visto tanto na superfície capsular como na de corte. Essa acentuação ocorria pela necrose hemorrágica do centro do lóbulo circundada por um halo branco-amarelado. O Eqüino 12 e o controle não apresentaram alterações macroscópicas.

Alterações extra-hepáticas foram bastante regulares e semelhantes em todos os eqüinos necropsiados, excetuando-se o Eqüino 12 que apresentou alterações relativas à ruptura gástrica (peritonite aguda) e o Eqüino 3 que apresentou um quadro anatomopatológico distinto. Todos os outros eqüinos apresentaram icterícia. Petéquias e sufusões foram vistas no tecido subcutâneo de cinco equiinos $(6,9,10,13$ e 14) e com localização subendocárdica em sete eqüinos $(6,7,9-11,13$ e 14), mais pronunciadas no ventrículo esquerdo. Sufusões subpleurais principalmente nos espaços intercostais foram vistas nos Equiinos 6 e 10. Hemorragias nas serosas e mucosas do aparelho digestivo foram observadas em sete eqüinos $(6,7,9-13$ e 14). Essas hemorragias apresentavam apenas pequenas variações quanto à localização e à intensidade (Quadro 5).

Lesões edematosas foram também freqüentemente observadas, variando apenas levemente quanto à intensidade e à
Quadro 6. Intoxicação experimental por Senecio brasiliensis em equiinos. Lesões macroscópicas extra-hepáticas. Distribuição dos edemas em oito eqüinos intoxicados ${ }^{a}$

\begin{tabular}{|c|c|c|c|c|c|c|c|c|}
\hline \multirow[t]{2}{*}{ Órgão ou tecido } & \multicolumn{8}{|c|}{ Eqüino } \\
\hline & 02 & 06 & 07 & 09 & 10 & 11 & 13 & 14 \\
\hline Saco pericárdico & + & - & + & + & - & + & - & + \\
\hline Cavidade torácica & + & - & - & + & - & + & - & - \\
\hline $\begin{array}{l}\text { Cavidade abdominal } \\
\text { Mucosas e submucosas }\end{array}$ & + & - & - & + & + & + & - & + \\
\hline Estômago & - & - & - & - & - & + & - & - \\
\hline Íleo & & - & - & + & + & + & + & + \\
\hline Cólon maior & - & + & + & + & + & + & + & + \\
\hline Ceco & - & + & + & + & - & + & + & + \\
\hline Outros tecidos & & & & & & & & \\
\hline $\begin{array}{l}\text { Peritônio, mesentério, } \\
\text { tecido perpancreático }\end{array}$ & - & + & + & + & + & + & - & - \\
\hline Tecido subcutâneo & - & - & + & - & - & - & - & + \\
\hline
\end{tabular}

localização (Quadro 6). Em dois eqüinos (7 e 14) observou-se edema subcutâneo das partes ventrais, em quatro (Eqüinos 7 , 9, 11 e 14) hidropericárdio e em dois (Eqüinos 9 e 11), discreto hidrotórax. Na cavidade abdominal de quatro eqüinos $(9$, 10,11 e 14) havia pequena quantidade de liquido âmbar ou serossanguiinolento. Marcado edema era visto na mucosa e submucosa do intestino delgado e grosso. Envolvendo os tecidos peripancreáticos de três eqüinos (7, 9 e 10) e ligamentos gastroesplênico (Eqüino 10) e gastroesofágico (Eqüino 7) havia discreto edema. No Eqüino 3 observou-se espessamento e avermelhamento da mucosa do cólon maior; a mucosa tinha um aspecto rugoso e continha focos branco-amarelados de $0,3-1 \mathrm{~cm}$ de diâmetro distribuídos aleatoriamente.

\section{Histopatologia}

Biópsias hepáticas. Os Eqüinos 1, 4, 5 e 8 não apresentaram alterações nas biópsias. $\mathrm{O}$ Eqüino 2 mostrou as primeiras alterações somente na biópsia realizada aos 498 dias após o início da administração da planta (AIAP) e consistiam de vacuolização do núcleo dos hepatócitos e hepatomegalocitose. No Eqüino 3 observaram-se as primeiras alterações nos hepatócitos aos145 AIAP e consistiam de vacúolos no núcleo. Aos 174 dias AIAP essas lesões apareceram acrescidas de algumas figuras de hepatomegalocitose; aos 199 dias AIAP observou-se necrose individual de hepatócitos associada a acúmulos de polimorfonucleares neutrófilos (PMNs). Aos 251 dias AIAP as lesões acima descritas haviam progredido, apareciam pseudoinclusões hialinas no núcleo de hepatócitos e, pelo tricrômico de Masson, percebia-se discreta proliferação de tecido conjuntivo nos espaços-porta. Nas biópsias hepáticas realizadas aos 66, 69 e 80 dias AIAP no Eqüino 6, havia necrose individual de hepatócitos que apareciam como glóbulos dissociados de outros hepatócitos adjacentes, fortemente acidofílicos, picnóticos ou sem núcleo; pequena quantidade de hemossiderina era vista no citoplasma de alguns hepatócitos e de células de Kupffer. Aos 89 dias AIAP as lesões descritas anteriormente estavam acrescidas de vacuolização dos núcleos de hepatócitos. Aos 110 dias AIAP observou-se necrose centrolobular associada à congestão e 
Quadro 7. Intoxicação experimental por Senecio brasiliensis em eqüinos. Principais lesões histológicas e seus graus de intensidade no fígado dos eqüinos intoxicados

\begin{tabular}{|c|c|c|c|c|c|c|c|c|c|}
\hline & \multicolumn{9}{|c|}{ Eqüino } \\
\hline & 2 & 3 & 6 & 7 & 9 & 10 & 11 & 13 & 14 \\
\hline Megalocitose & $+++^{\mathrm{a}}$ & +++ & $++^{\mathrm{b}}$ & $+^{c}$ & $-d$ & - & - & - & - \\
\hline Fibrose & ++ & ++ & + & + & - & - & - & - & - \\
\hline Necrose & - & - & ++ & ++ & +++ & +++ & +++ & +++ & +++ \\
\hline Hemossiderose & +++ & - & +++ & ++ & + & + & ++ & - & + \\
\hline Estase biliar & + & - & + & ++ & + & ++ & + & + & + \\
\hline Degeneração gordurosa & - & - & + & ++ & ++ & ++ & + & ++ & ++ \\
\hline Inclusões acidofílicas no núcleo & ++ & ++ & + & - & - & - & - & - & - \\
\hline Necrose focal com acúmulo de $\mathrm{PMNs}^{\mathrm{e}}$ & + & ++ & ++ & + & - & + & - & + & - \\
\hline
\end{tabular}

aLesão acentuada, b + + lesão moderada, 'lesão discreta, ${ }^{\mathrm{d}}$ ausência de lesão, ${ }^{\mathrm{e}}$ polimorfonucleares neutrófilos.

hemorragia. Discreta fibrose periportal era evidenciada pela técnica de Masson. No Eqüino 7, aos 47 dias AIAP havia necrose hepatocelular individual associada a discreto infiltrado de PMNs e raras figuras de hepatomegalocitose. Aos 76 dias, AIAP essas lesões eram acrescidas de hepatócitos com núcleos vacuolizados e com cromatina dispersa. No Eqüino 11, as primeiras alterações morfológicas foram observadas na biópsia hepática realizada aos 23 dias AIAP e eram constituídas de necrose hepatocelular individual associada a infiltrado de PMNs; quadro histológico semelhante foi observado aos 30 dias AIAP. O Eqüino 13 já mostrava necrose centrolobular na biópsia realizada um dia AIAP, caracterizada por perda de hepatócitos e hepatócitos em picnose e cariorrexia; além disso, percebia-se necrose individual de hepatócitos com as características anteriormente descritas. Esses hepatócitos necróticos eram distribuídos aleatoriamente pelos lóbulos; havia ainda alguns hepatócitos com vacúolos intranucleares e alguns PMNs disseminados pelos sinusóides; na biópsia realizada 2 dias AIAP, extensas áreas de necrose, associadas à hemorragia eram vistas na maioria dos lóbulos. $\mathrm{O}$ infiltrado de PMNs persistia de forma disseminada e incrementada.

Material de necropsia. As principais alterações hepáticas, microscópicas e seus graus de intensidade encontram-se resumidas no Quadro 8.

A lesão encontrada na maioria dos fígados dos eqüinos intoxicados pela planta foi de necrose coagulativa com hemorragia do lóbulo. Essa necrose variava em intensidade. Nos Eqüinos 9-11, 13 e 14 a necrose era acentuada e por vezes atingindo todo o parênquima de alguns lóbulos ou poupando apenas alguns hepatócitos na periferia dos lóbulos; no entanto; freqüientemente esses hepatócitos periféricos eram vacuolizados e positivos na coloração de Sudan III. Nos Eqüinos 6 e 7 era definidamente centrolobular e de intensidade moderada, considerando a quantidade de parênquima lobular atingida (Quadro 7). Os Eqüinos 2, 3, 6 e 7 mostraram lesões com predominância de fibrose e megalocitose de hepatócitos (Fig.2) sobre as lesões necróticas. A fibrose por vezes formava pontes entre duas ou mais tríades portais. Pseudo-inclusões acidofilicas intranucleares que pareciam ser envoltas por membrana nuclear (Fig.3) foram vistas no fígado de três eqüinos (2, 3 e 6$)$. Nesses três eqüinos as lesões hepáticas eram mínimas ou ausentes. Em cinco eqüinos $(3,6$, 7,10 e 13) eram observados pequenos grupos de hepató- citos necróticos ou degenerados associados à infiltração por PMNs.

Havia estase biliar nos Eqüinos 22, 6, 7, 9-11, 13 e 14. Hemossiderose em hepatócitos e macrófagos foi observada

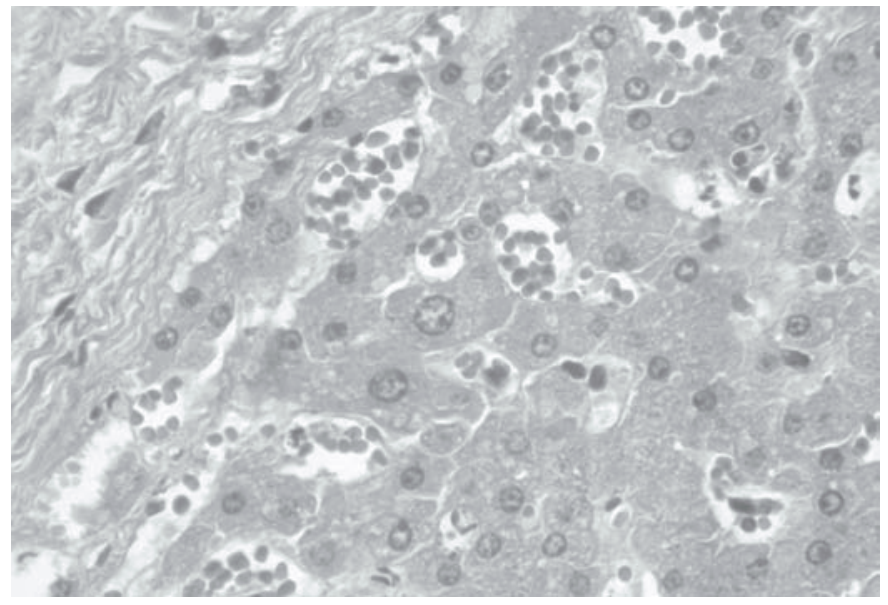

Fig.2. Megalocitose de hepatócitos próximos a espaço porta, na intoxicação experimental por Senecio brasiliensis (Eqüino 2). HE, obj.40.

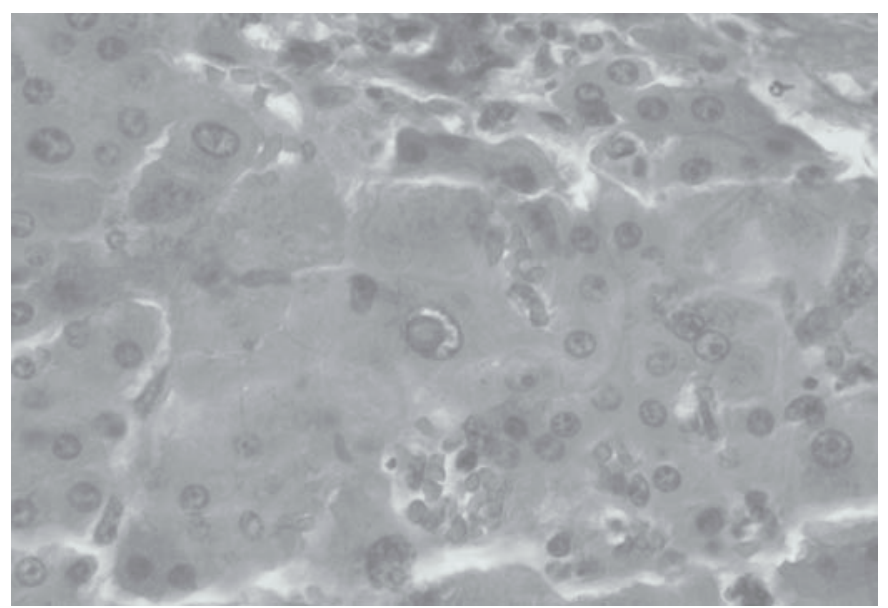

Fig.3. Hepatócito mostrando megalocitose núcleo vacuolizado e glóbulo eosinofílico intranuclear envolto por membrana nuclear, na intoxicação experimental por Senecio brasiliensis (Eqüino 2). HE, obj.40. 
na maioria dos fígados (Eqüinos 2, 6, 7, 9-11 e 14). No linfonodo de cinco eqüinos $(6,7,9,11$ e 14) havia edema com dispersão das células dos folículos; essa lesão era acompanhada de hemorragia no caso do Eqüino 14 . No baço de sete eqüiinos (6, $7,9,10,11,13$ e 14) havia congestão e grande acúmulo hemossiderina. $O$ pulmão dos Eqüinos 6 e 11 apresentava pequenos focos hemorrágicos e, no de quatro equiinos $(6,9$, 11 e 14), apareciam variados graus de edema, porém nunca de forma acentuada. Marcado edema da mucosa e submucosa do jejuno, íleo, cólon maior e ceco foi observado em sete eqüiinos $(6,7,9-11,13$ e 14) geralmente associado à dilatação dos linfáticos da submucosa. Focos hemorrágicos eram vistos na mucosa do cólon maior de três eqüinos $(9,11$ e 13) e na mucosa do cólon menor do Eqüino 13. Na mucosa e submucosa do cólon maior do Eqüino 3 viam-se áreas necróticas multifocais circundadas por reação inflamatória granulomatosa com formação de células gigantes tipo corpo estranho. Essas lesões estavam associadas à congestão e à hemorragia. Na região das criptas observavam-se larvas de nematódeos em meio a discreta reação inflamatória neutrofílica e eosinofílica.

No encéfalo de seis eqüinos (2, 3, 6, 7, 10 e 13), observaram-se alterações astrocitárias restritas à substância cinzenta e, predominantemente, no córtex telencefálico. Esses astrócitos apareciam mais numerosos quando comparados aos eqüinos não afetados e tinham o núcleo grande $(15-20 \mu \mathrm{m})$ arredondado, com cromatina ausente ou muito rarefeita e carioteca bem demarcada por marginação da cromatina; e por vezes esférulas de cromatina, lembrando nucléolos, colocavam-se contra a parte interna da carioteca. O citoplasma desses astrócitos era indistinto. Astrócitos com essas características apareciam freqüientemente aos pares e, em alguns locais, o núcleo tinha forma ovóide e carioteca tortuosa, dando-lhe um aspecto lobulado.

\section{DISCUSSÃO}

Esse estudo demonstra que Senecio brasiliensis é tóxico para equiinos. De 14 cavalos que receberam a planta, nove morreram em conseqüência da intoxicação. $O$ desenvolvimento das lesões hepáticas (necrose ou fibrose) esteve relacionado com a quantidade e período de tempo em que a planta foi administrada. Administrações de quantidades relativamente grandes $(0,87 \%, 1,5 \%, 1,74 \%, 3,0 \%$ e $3,5 \%$ do peso corporal) por períodos relativamente curtos (1-7dias) causaram necrose enquanto doses ainda que maiores $(9,30 \%, 7,42 \%$ e $8,909,66 \%$ do peso corporal) administradas por períodos mais longos (respectivamente 43 e 17 administrações semanais e 285 e 82 administrações diárias) causaram fibrose. Essa é uma característica da ação dos APs; doses únicas elevadas causam a morte dos animais em poucas horas a três dias, enquanto doses menores ingeridas por períodos prolongados produzem uma lesão mais crônica que pode progredir mesmo quando a administração da planta já foi suspensa (McLean 1970, Tokarnia \& Döbereiner 1984). Um exemplo disso ocorreu com o Eqüino 2. Nesse eqüino, a primeira alteração na biópsia apareceu 438 dias após a primeira administração da planta e cerca de 4 meses após a última administração semanal de $S$. brasiliensis. Esse eqüino morreu em consequiência da intoxicação cerca 240 dias após ter sido detectada a primeira lesão na biópsia hepática.

Os sinais clínicos da intoxicação por Senecio brasiliensis em eqüinos incluíram icterícia, perturbações neurológicas e, em um caso, diarréia. Nos casos de evolução clinica mais longa houve perda de peso. Sinais neurológicos semelhantes aos descritos nos cavalos deste experimento são freqüientes na intoxicação por APs em eqüinos (Kalkus et al. 1925, Clawson 1933, Steyn 1934, Carvalho \& Maugé 1946, Curial \& Guimarães 1958, Kingsbury 1964, Fowler 1965; Tennant et al., 1973, Araya \& González 1979, Qualls Jr 1980, Giles 1983) e embora sejam descritos também em bovinos intoxicados por Senecio spp (Barros et al.1992), parecem ser mais freqüentes em eqüinos. Esses sinais neurológicos são secundários à insuficiência hepática em eqüinos (Tennant et al. 1973, Angsubhakorn et al. 1981) e em outras espécies (Cullen 2007), incluindo pessoas (Frosch et al. 2005) em doenças hepáticas difusas não especificas, sem relação com a intoxicação por APs. Alterações neurológicas em conseqüência da insuficiência hepática são, usualmente, referidas como encefalopatia hepática (EH) e embora a causa seja complexa, de modo geral, é aceito que a lesão difusa impeça o fígado de metabolizar substâncias tóxicas elaboradas no tubo gastrintestinal (Cullen 2007). As lesões histológicas do encéfalo na EH variam entre as espécies estudadas. Em pessoas, basicamente descreve-se edema caracterizado por aumento dos espaços perivasculares e pericelulares, necrose isquêmica de neurônios e aparecimento de astrócitos Alzheimer tipo 2 que podem não ocorrer na insuficiência hepática fulminante. Essas lesões são restritas à substância cinzenta, principalmente córtex telencefálico (Frosch et al. 2005). Eqüinos afetados por aflatoxicose espontânea (Angsubhakorn et al. 1981) e intoxicados experimentalmente por Senecio vulgaris (Qualls Jr 1980) e Crotalaria retusa (Nobre et al. 2004) desenvolvem EH com alterações morfológicas semelhantes ao que é descrito para pessoas (Frosch et al. 2005). No entanto em bovinos (Driemeier \& Barros 1992) e ovinos (Ilha et al. 2001) a lesão encefálica da EH difere tanto na morfologia (edema intramielínico referido como degeneração esponjosa) quanto na distribuição (principalmente na substância branca)

A icterícia foi um achado clínico constante nos equiinos fatalmente intoxicados nesse experimento e poderia ter sido de origem hepática ou devido à hemólise intravascular que ocorre por causas não bem esclarecidas em eqüinos com insuficiência hepática (Fowler 1965, Tennant et al. 1973).

Fotodermatite hepatógena não ocorreu nos equiinos deste experimento, embora alguns deles tivessem partes da pele despigmentadas, todos tivessem acesso diário a pasto verde e passassem longos períodos ao sol. Essa alteração tem sido descrita na insuficiência hepática em eqüinos (Fowler 1965, Tennant et al. 1973, Qualls Jr 1980, Gava \& Barros 1997).

No quadro macroscópico de oito eqüinos intoxicados por S. brasiliensis predominaram lesões do fígado associadas a edema e hemorragias. Nas lesões do fígado notou-se principalmente necrose zonal caracterizada por acentuação do padrão lobular e consistência discreta ou moderadamente mais firme em quatro casos. 
Distúrbios na hemostasia ocorrem em casos de doença hepatocelular difusa (Cullen 2007) e têm sido descritos em hepatopatias tóxicas por aflatoxinas em cavalos (Angsubhakorn et al. 1981 e em outras doenças hepáticas difusas, independente da etiologia (Tennant et al. 1973, Cullen 2007). As hemorragias foram mais freqüentes e intensas nos eqüinos com lesão aguda extensa do fígado e provavelmente não foram causadas pelo decréscimo na síntese de fatores da coagulação por coagulopatia de consumo. O contato de grande quantidade de sangue com extensas áreas de lesão endotelial no fígado levam à ativação exagerada dos fatores da coagulação e seu consumo (Cullen 2007)

Edema, principalmente na submucosa do tubo gastrintestinal foram achados de necropsia regularmente encontrados nos eqüinos que morreram da intoxicação, nesse experimento. Esses achados são comumente descritos associados à intoxicação por APs em eqüinos (Kalkus et al. 1925, McLintock \& Fell 1953, Hill \& Martin 1958, Qualls Jr 1980, Elcock \& Oehme 1982). Edemas em geral ocorrem por obstrução linfática, hipoproteinemia, elevação da pressão hidrostática venular e aumento da permeabilidade na microcirculação (Mosier 2007). Os dois últimos mecanismos poderiam estar envolvidos na produção do edema nos eqüinos desse experimento. $\mathrm{O}$ aumento da permeabilidade dos vasos já foi descrito como ação de certos tipos de APs (McLean 1970); como 30\% da excreção dos APs se dá pela bile (McLean 1970), sua ação sobre a mucosa intestinal seria compreensível.

Os achados microscópicos mais freqüentes nos fígados dos cavalos que morreram em conseqüência da intoxicação foram necrose hemorrágica aguda extensa em cinco casos (Eqüinos 9-11 e 14) e subaguda em dois (Eqüinos 6 e 7). Neste estudo, as lesões hepáticas foram classificadas como agudas baseando-se na extensa necrose, na ausência reações proliferativas conjuntivas ou hepatomegalocitose, e crônicas quando predominaram fibrose e hepatomegalocitose. Nos casos em que a necrose coexistia com reações proliferativas (Eqüinos 6 e 7) a alteração foi considerada subaguda. Uma comparação das lesões hepáticas dos eqüinos deste estudo com as lesões hepáticas produzidas por $S$. brasiliensis em bovinos (Tokarnia \& Döbereiner 1984) indica que a fibrose é menos proeminente em eqüinos do que em bovinos e que a megalocitose de hepatócitos é mais pronunciada em eqüinos do que em bovinos

O Eqüiino 3 mostrou diarréia associada à lesão granulomatosa do intestino associada a pequenos estrôngilos (cisastostomíase). Embora esse equiino tivesse lesões hepáticas características das produzidas por APs e avançadas, diarréia fatal por pequenos estrôngilos já foi descrita (Rech et al. 2003) como causa de morte em equiinos e não pode ser afastada como a causa da morte neste caso.

Neste estudo, foram vistos no fígado corpúsculos eosinofílicos no interior do núcleo dos hepatócitos. Noutros casos o núcleo estava vazio, com cromatina marginada e nucléolo evidente. Alterações como essas têm sido observadas nas intoxicações por APs em eqüinos (Garrett et al. 1984), bovinos (Barros et al. 1992, Barros et al. 2007) e ovinos (Barros et al 1989, Ilha et al. 2001); esses corpúsculos eosinofi1 icos intranucleares são interpretados como invaginações citoplasmáticas (Barros et al. 1992) e por isso referidos como pseudoinclusões.

A biópsia hepática demonstrou que pode ser um método auxiliar no diagnóstico da doença pré-clínica. Lesões incipientes como vacuolização nuclear, descritas em eqüinos (Garrett et al. 1984) e bovinos (Barros 2007) como a alteração precoces na intoxicação por Senecio spp., necrose individual de hepatócitos, "inclusões" acidofílicas hepatocitárias intranucleares e megalocitose, puderam ser percebidas pela biópsia antes do aparecimento dos sinais clínicos.

Há variações entre espécies e mesmo entre animais da mesma espécie quanto a susceptibilidade aos APs (Hooper 1978). Isso pôde ser confirmado neste experimento. De dois eqüinos que receberam administrações diárias de $5 \mathrm{~g} / \mathrm{kg}$ da planta, um (Eqüino 14) mostrou sinais clínicos após a quinta administração, morrendo com uma evolução clínica de três dias, após ter consumido um total correspondente em planta verde de $3,5 \%$ de seu peso. $O$ outro (Eqüino 8 ) recebeu 30 administrações da planta, (total de $15 \%$ de seu peso) e nunca apresentou alterações nas biópsias hepáticas, mesmo 317 dias após a última administração. Não apresentou, também, sinais clínicos durante os 335 dias em que foi observado. Por outro lado o Eqüino 3 apresentou lesões crônicas à necropsia, após 284 administrações diárias de $0,3125 \mathrm{~g} / \mathrm{kg}(8,9 \%$ de seu peso), enquanto que o Eqüino 4, que recebeu 240 administrações diárias de $0,625 \mathrm{~g} / \mathrm{kg}$ (15\% de seu peso), nunca apresentou sinais clínicos nem lesões nas biópsias hepáticas realizadas 202 dias após a última administração da planta. O Equiino 6 , que recebeu administrações semanais por 17 semanas (equivalentes $7,42 \%$ de seu peso), morreu dois dias após a última administração, com quadro clínicopatológico típico de seneciose. Finalmente, o Eqüino 5, que recebeu uma administração de $10 \mathrm{~g} / \mathrm{kg}$ (1\% de seu peso), não adoeceu nem mostrou alterações na última biópsia hepática realizada 147 dias após a última administração da planta, mas o Eqüino 9 morreu quatro dias após ter recebido uma administração de $8,5 \mathrm{~g} / \mathrm{kg}$ da planta $(0,87 \%$ de seu peso), com sinais clínicos, de necropsia e histopatologia característicos da intoxicação pela planta.

Comparando-se os dados deste estudo com os de outros experimentos realizados com $S$. brasiliensis em bovinos (Tokarnia \& Döbereiner 1984) e ovinos (Barros et al. 1989), observa-se que a susceptibilidade do eqüino é aproximadamente equivalente à do bovino e bem maior que a do ovino.

\section{REFERÊNCIAS}

Angsubhakorn S., Poomvises P., Romruen K. \& Newberne P.M. 1981. Aflatoxicosis in horses. J. Am. Vet. Med. Assoc. 178:274-278.

Araya O. \& González S. 1979. Intoxicacion de caballos con Senecio erraticus. Gac. Vet., Bs Aires, 41:743-5.

Barros C.S.L., Driemeier D., Pilati C., Barros S.S. \& Castilhos L.M.L. 1992. Senecio spp. poisoning in cattle in southern Brazil. Vet. Human Toxicol. 34:241-246.

Barros C.S.L., Metzdorf L., Santos M.N., Barros S.S. \& Peixoto P.V. 1989. Intoxicação experimental por Senecio brasiliensis (Compositae) em ovinos. Pesq. Vet. Bras. 9:55-67. 
Barros C.S.L., Metzdorf L.L. \& Peixoto P.V. 1987. Ocorrência de surtos da intoxicação por Senecio brasiliensis (Compositae) em bovinos no Rio Grande do Sul. Pesq. Vet. Bras. 7:101-107.

Barros C.SL., Castilhos L.M.L., Rissi D.R., Kommers G.D. \& Rech R.R. 2007. Biópsia hepática no diagnóstico da intoxicação por Senecio brasiliensis em bovinos. Pesq. Vet. Bras. 27(1):53-60.

Carvalho G.S.T. \& Maugé G.C. 1946. Ação tóxica do "Senecio brasiliensis", Lessing fam. Compositae. Revta Fac. Med. Vet., São Paulo, 3:131-136.

Clawson A.B. 1933. The American groundsells species of Senecio as stock poisoning plants. Vet. Med. 28:105-110.

Cullen J.M. 2007. Liver, biliary system and exocrine pancreas, p.393-461. In: McGavin M.D. \& Zachary J.F. (ed.), Pathologic Basis of Veterinary Disease. $4^{\text {th }}$ ed. Mosby Elsevier, St Louis. 1476p.

Curial O. \& Guimarães J.P. 1958. Cirrose hepática enzoótica no cavalo. Mem Inst. Oswaldo Cruz 56:635-643 + 5 il.

Driemeier D. \& Barros C.S.L. 1992. Intoxicação experimental por Senecio oxyphyllus (Compositae) em bovinos. Pesq. Vet. Bras. 12:33-42.

Driemeier D., Barros C.S.L. \& Pilati C. 1991. Seneciose em bovinos. Hora Vet., Porto Alegre, 10:23-30.

Elcock L. \& Oehme F.W. 1982. Senecio poisoning in horse: A summary. Vet. Human Toxicol. 24:122-123.

Fowler M.E. Clinical manifestation of primary hepatic insufficiency in the horse. J. Am. Vet. Med. Assoc. 147:55-64.

Frosch M.P., Anthony D.C. \& De Girolami U. 2005. The Central nervous system, p.1347-1419. In: Kumar V., Abbas A.B. \& Fausto N. (ed.), Robbins and Cotran Pathologic Basis of Disease. $7^{\text {th }}$ ed. Elsevier Saunders, Philadelphia. 1525p.

Garrett B.J., Holtan D.W., Cheeke P.R., Schmitz J.A. \& Rogers Q.R. 1984. Effects of dietary supplementation with butylated hydroxynisole, cysteine, and vitamins B on tansy ragwort (Senecio jaeobaea) toxicosis in ponies. Am. J. Vet. Res. 4:459-464.

Gava A. \& Barros C.S.L. 1997. Senecio spp. poisoning in horses in southern Brazil. Pesq. Vet. Bras. 17:36-40.

Giles C.J. 1983. Outbreak of ragwort (Senecio jaeobea) poisoning in horses. Eq. Vet. J. 15:248-50.

Hill K.R. \& Martin H.M. 1958. Hepatic veno-occlusive disease and megalocytosis in Senecio poisoning of horses. Brit. Vet. J. 114:345-350.

Hooper P.T. 1978. Pyrrolizidine alkaloid poisoning-pathology with particular reference to differences in animal and plant species, p.162-176. In: Keeler R.F., Van Kampen K.R.\& James L.F. (ed.), Effects of Poisonous Plants on Livestock. New York, Academic Press. 600p.

Ilha M.R.S, Loretti A.P., Barros S.S. \& Barros C.S.L. 2001. Intoxicação espontâ- nea por Senecio brasiliensis (Asteraceae) em ovinos. Pesq. Vet. Bras. 21:123138.

Kalkus J.W., Trippeer H.A. \& Fuller J.R. 1925. Enzootic hepatic cirrhosis of horse (Walking disease) in the Pacific Northwest. J. Am. Vet. Med. Assoc. 21:285-99.

Kingsbury J.M. 1964. Poisonous Plants of the United States and Canada. Prentice Hall, Englewood Cliffs, N.J. 626p.

Liddell J.R., Stermitz F.R. \& Barros C.S.L. 1992. Pyrrolizidine alkaloids from Senecio oxyphyllus, a Brazilian poisonous plant. Bioch. System. Ecol. 20:393.

McLean E.K. 1970. The toxic actions of pyrrolizidine (Senecio) alkaloids. Pharm. Rev. 33:429-483.

McLinctock J. \& Fell B.F. 1953. A case of acute ragwort poisoning in the horse. Vet. Rec. 65:319-20.

Méndez M.C., Riet-Correa F. \& Schild A.L. 1987. Intoxicação por Senecio spp. (Compositae) em bovinos no Rio Grande do Sul. Pesq. Vet. Bras. 7:51-6.

Méndez M.C., Riet-Correa F., Schild A.L. \& Martz W. 1990. Intoxicação experimental por cinco espécies de Senecio em bovinos e aves. Pesq. Vet. Bras. 10:63-69.

Mosier D.A. 2007. Vascular disorders and thrombosis, p.63-99. In: McGavin M.D. \& Zachary J.F. (ed.), Pathologic Basis of Veterinary Disease. $4^{\text {th }}$ ed. Mosby Elsevier, St Louis. 1476p.

Nobre V.M.T., Riet-Correa R., Barbosa Filho J.M., Dantas A.F.M., Tabosa I.M. \& Vasconcelos J.S. 2004. Intoxicação por Crotalaria retusa (Fabaceae) em equíídeos no semi-árido da Paraíba. Pesq. Vet. Bras. 24:132-143.

Qualls Jr C.W. 1980. Senecio vulgaris toxicity in the horse. PhD Thesis, University of California, Davis. 179p.

Rech R.R., Oliveira F.N., Raffi M.B. \& Barros C.S.L. 2003. Diarréia associada a ciatostomíase em eqüino. $11^{\circ}$ Enapave, Botucatu, p.133. (Resumo)

Riet-Correa F. \& Medeiros R.M.T. 2001. Intoxicações por plantas em ruminantes no Brasil e no Uruguai: importância econômica, controle e riscos para a saúde pública. Pesq. Vet. Bras. 21:38-42.

Rissi D.R., Rech R.R., Pierezan F., Gabriel A.L., Trost M.E., Brum J.S., Kommers G.D. \& Barros C.S.L. 2007. Intoxicação por plantas e micotoxinas associadas a plantas em bovinos no Rio Grande do Sul: 461 casos. Pesq. Vet. Bras. 27(7):261-268.

Steyn D.G. 1934. The Toxicology of Plants in South Africa. Central News Agency, South Africa, p.439-493.

Tennant B., Evans C.D., Schwartz L.W., Gribble D.H. \& Kaneko J.J. 1973. Equine hepatic insufficiency. Vet. Clin. North Am. 3:279-289.

Tokarnia C.H. \& Döbereiner J. 1984. Intoxicação experimental por Senecio brasiliensis (Compositae) em bovinos. Pesq. Vet. Bras. 4:39-65. 